\title{
BREVE HISTÓRIA DOS SLOGANS POLÍTICOS NAS ELEIÇÕES DO BRASIL REPUBLICANO
}

\section{Brief history of politician slogans in elections of Republican Brazil}

\author{
Adolpho Queiroz ${ }^{1}$ \\ Carlos Manhanelli ${ }^{2}$
}

\begin{abstract}
Resumo
Este artigo pretende recuperar a memória dos slogans eleitorais no Brasil, na ótica da propaganda política, mostrando de que forma essas palavras ajudam na construção da imagem eleitoral e na comunicação política dos candidatos. O estudo presente tem como objetivo a análise das representações discursivas, políticas e dos valores contidos nos slogans das eleições presidenciais, estaduais e municipais. Os resultados do estudo incidirão na análise da diferenciação discursiva, política, ideológica e dos valores contidos nos slogans de campanha. Do ponto de vista metodológico, este estudo utiliza a análise de conteúdo, percepções lingüísticas e visão histórica de sua evolução no Brasil.
\end{abstract}

Palavras-chave: slogans, propaganda política, Brasil, discursos.

\begin{abstract}
This article seeks to recover the memory of the election slogans in Brazil, in the view of political propaganda, showing how these words help build the image of the electoral and political man. This study aims at analyzing the discursive representations, policies and the values contained in the slogans of the presidential elections, government and mayors .The results of the study will focus on the analysis of differentiation discursive, political, ideological and values contained in the campaign slogans. From the methodological point of view, this study uses content analysis, insights and linguistic historical overview of its evolution in Brazil.
\end{abstract}

Keywords: slogans, police propaganda, Brazil, discourses.

\section{Resumen}

\footnotetext{
${ }^{1}$ Adolpho Queiroz é Pós-Doutor em Comunicação pela Universidade Federal Fluminense/RJ; Doutor em Ciências da Comunicação pela Universidade Metodista de São Paulo, onde atua no Programa de PósGraduação em Comunicação; é Presidente da POLITICOM, Sociedade Brasileira dos Pesquisadores e Profissionais em Comunicação e Marketing Político

${ }^{2}$ Carlos Manhanelli é Mestre em Comunicação pela Universidade Metodista de São Paulo e presidente da ABCOP, Associação Brasileira de Consultores Políticos.
} 
Esto artículo tiene la intención de recuperar la memoria de los slogans electorales en Brasil, en la percepción de la propaganda política, mostrando de que forma estas palabras ayudan en la construcción del imagen electoral y política de los candidatos. El estudio tiene como objectivo el analisis de las representaciones discursivas, políticas y de los valores contados el los slogans de las elecciones presidenciales, de províncias y municipales. Los resultados del estudio incidiron en el analisis de la diferenciación discursiva, política y ideológica y de los valores contenidos en los slogans de la propaganda. Del punto de vista metodológico, esto estudio utiliza el analisis del contenido, percepciones linguísticas y la visión histórica de suya evolución en Brasil.

Palabras Clave: slogans, propaganda polític, Brasil, discursos.

\section{INTRODUÇÃO}

Embora a história da propaganda política no Brasil seja recente, tem sido modesto o estudo e a recuperação das contribuições do slogan como peça essencial de uma campanha política. Do humor dos tempos da República Velha, que ironizava o candidato Artur Bernardes pelos seus hábitos etílicos (imprimindo-lhe o rótulo de "Seu Mé”, isto é, "Seu Mel", utilizando-se o termo "Mel" ou "Mé" para qualificar quem tomava aguardente em excesso), passando por um dos mais emblemáticos de todos os slogans, construído para dar a Juscelino Kubitscheck de Oliveira a imagem de empreendedor, que faria o Brasil avançar "50 anos em 5"; ou ainda o popular "Lula lá", incentivando o voto ao candidato Luis Inácio Lula da Silva na sua campanha presidencial, todos esses textos deram aos slogans eleitorais uma configuração nova e importante na história recente da propaganda política no país.

A definição sobre slogan está resumida em ser uma frase ou sentença que defina as qualidades do produto. Um slogan é uma frase de fácil memorização usada em contexto político, religioso ou comercial como uma expressão repetitiva de uma idéia ou de um propósito. Um slogan politíco geralmente expressa um objetivo ou alvo - "Trabalhadores do 
mundo, uni-vos!"3 -, enquanto um slogan publicitário é mais frequentemente usado como uma identificação de fácil memorização, agregando um valor único à empresa, ao produto ou ao serviço, sendo esse valor concreto ou não - como o exemplo da marca de cerveja que se auto-denominava como "A número 1".

Slogans variam do escrito ao visual, do cantado ao vulgar. Quase sempre sua natureza simples e retórica deixa pouco espaço para detalhes e, como tal, servem talvez mais a uma expressão social de propósito unificado, do que a uma projeção para uma pretendida audiência. Slogans são atrativos particularmente na era moderna de bombardeios informacionais de numerosas fontes da mídia. A palavra vem de slaugh-ghairm (se pronuncia slogorm), do gaélico escocês que designa a expressão "grito de guerra" (Reboul 1975 e Lasswell 1982), como no filme conhecido Coração Valente ${ }^{4}$, que é uma das formas de representação do período em que surgem os slogans, alguns dos quais pronunciados durante aquela produção cinematográfica.

O slogan publicitário é uma curta mensagem usada como uma identificação de fácil memorização agregando sentido a um produto ou serviço. O slogan compõe o que se chama de suporte ou complementação de uma determinada mensagem. O brado de guerra, grito usado nos antigos clãs para inspirar os seus membros a lutarem pela preservação do grupo, adequa-se à guerra existente no mercado e na disputa pelo consumidor.

Modernamente, a publicidade e a propaganda utilizam o slogan como forma de destacar os atributos, vantagens entre outras na complementação de uma mensagem comercial. Na propaganda o slogan é uma frase mnemônica, tem finalidade de se manter na mente do consumidor ratificando certas características. Entre elas, os traços da: a) personalidade -que conceitua o produto frente ao seu usuário, por exemplo: "Com o produto X, você vai ao sucesso!”; b) da identidade ou da denúncia dos atributos do produto, que é uma das características mais importantes a ser somada ao efeito de sentido causado pela memorização, que tais frases buscam construir. O slogan está associado à imagem, à linguagem escrita e à estética, transcendendo a materialidade, o produto ou o serviço,

\footnotetext{
${ }^{3}$ O slogan político "Trabalhadores do mundo, uni-vos!", um dos mais famosos gritos de protesto do socialismo, vem do Manifesto Comunista de Karl Marx e Friedrich Engels. A real tradução é normalmente tida como "Proletários de todos os países, uni-vos!" É algumas vezes estendida para "Trabalhadores do mundo, uni-vos, vós não tendes nada a perder a não ser vossos grilhões", misturando as três últimas frases do Manifesto Comunista. A máxima socialista foi adotada como lema da então União das Repúblicas Socialistas Soviéticas, dissolvida no final de $1991 . \quad 0$ Obtido "http://pt.wikipedia.org/wiki/Trabalhadores_do_mundo,_uni-vos! É algumas vezes estendida para "Trabalhadores do mundo, uni-vos, vós não tendes nada a perder a não ser vossos grilhões", misturando as três últimas frases do Manifesto Comunista.A máxima socialista foi adotada como lema da então União das Repúblicas Socialistas Soviéticas, dissolvida no final de 1991.Obtido em "http://pt.wikipedia.org/wiki/Trabalhadores_do_mundo,_uni-vos!"

${ }^{4}$ Braveheart (Coração Valente), 1995, EUA, direção de Mel Gibson.
} 
transformando-se no afirmativo indicador dos atibutos enunciados no texto publicitário.

O bom slogan é curto e direto, expressando a história, a psicologia, o conceito da marca, empresa ou produto e ou serviços. ${ }^{5}$

Os slogans usados nas campanhas eleitorais devem se tornar o grito de guerra dos militantes partidários e, com certeza, não saem da cabeça de nenhum iluminado. Os bons slogans derivam das informações prestadas pelas pesquisas que detectam as qualidades já enxergadas no candidato e as valorizam, ou apregoam um conceito que se deseje reforçar sobre o candidato ou sobre sua plataforma-proposta, ou um desejo, necessidade, anseio ou precisão da população naquele momento eleitoral. Ele pode até derivar de uma expressão que esteja na moda na época de sua utilização, como: "Eu quero votar para Presidente" (Campanha Diretas Já em 1984).

Os slogans eleitorais devem ser de fácil lembrança, com palavras simples. Conter o nome do candidato é desejável. Rimas, trocadilhos e palavras bem humoradas ajudam no fator lembrança, como: "Não vote em branco, vote Negrão de Lima" (Campanha no Rio de Janeiro para Governador) e "Plante que o João Garante" (Presidente João Batista Figueiredo $-1980)$.

O slogan eleitoral ideal é aquele que passa para a população como um jargão popular, usado para expressar algum sentimento (Por algum tempo a indignação com as campanhas eleitorais era expressada com a famosa frase "Meu nome é Eneas"). O slogan pode também trazer um desejo que a população tenha manifestado possuir, em tal grau que justifique sua presença.

Um benefício sempre será bem vindo na estrutura de um bom slogan. "Vote para ser feliz" ou "Pra acabar com a molecagem". Um bom slogan também deve mostrar a diferença entre os candidatos: "Vote no brigadeiro, ele é bonito e é solteiro" (Brigadeiro Eduardo Gomes, eleição presidencial de 1945) ou "Collor é progresso" (1989).

Além de tudo isso, o bom slogan deve transmitir um sentimento positivo sobre o candidato: "Collor, um novo tempo vai começar", texto da campanha presidencial "Collor é progresso", 1989.

A estratégia deve se fazer presente também na hora de se criar um slogan. As pesquisas em 1990 mostravam que a clase média tinha medo de votar em Lula para Presidente. Assim nasceu o slogan que combatia esse conceito "Sem medo de ser feliz" (Lula, eleição de 1990).

O ideal é que um slogan expresse o que está no inconsciente coletivo da população e

\footnotetext{
${ }^{5}$ HTTP://www.wikipedia.org/wiki/slogan acessado em 28/11/2007 9:30h
} 
que possa maximizar esses sentimentos e emoções já percebidos. Para isso, os futuros candidatos devem ser orientados para que, antes de pensar em qual slogan utilizar, encomendem uma pesquisa para saber qual a imagem que a população tem dele. Quais as qualidades já são perceptíveis espontaneamente. A partir do resultado dessa pesquisa é que se deve, então, formatar um bom slogan com base no que for mais forte nas possibilidades, como apresentamos acima (expressão da moda, desejo da população, qualidade do candidato, imagem, mostrar a diferença), não se esquecendo do que faz a diferença em um bom slogan (fácil lembrança, expressar sentimento, ser positivo e estratégico).

Abaixo apresentamos tabelas com alguns slogans conhecidos e já citados, e outros nem tanto:

\begin{tabular}{|l|l|}
\hline \multicolumn{2}{|l|}{ Tabela 1: Campanhas Históricas } \\
\hline Slogan & Ano \\
\hline "Terra à vista!". Marinheiro na embarcação de Pedro Álvares & 1500 \\
Cabral -Campanha de conquistas coloniais de Portugal que dá & \\
origem ao Brasil; & \\
\hline $\begin{array}{l}\text { "O petróleo é nosso". Campanha Governamental de Getúlio } \\
\text { Vargas }\end{array}$ & 1950 \\
\hline
\end{tabular}

\begin{tabular}{|l|l|}
\hline Tabela 2: Campanhas Militares & Ano \\
\hline Slogan & 1970 \\
\hline “Brasil, ame-o ou deixe-o". Campanha do Governo Militar. & 1970 \\
\hline "Ninguém segura este país". Campanha do Governo Militar. & 1970 \\
\hline "Este é um país que vai pra frente”. Campanha do Governo Militar. & 1970 \\
\hline "Pra frente, Brasil”. Campanha da Copa do Mundo/México. & 1980 \\
\hline \begin{tabular}{l} 
"Plante que o João Garante”. Campanha Presidencial de João Batista \\
\hline "Eu te amo, meu Brasil”. Campanha do Governo Militar.
\end{tabular} & 1970 \\
\hline “As 200 milhas são nossas". Campanha do Governo Militar. & 1970 \\
\hline
\end{tabular}




\begin{tabular}{|c|c|}
\hline Slogan & Ano \\
\hline $\begin{array}{l}\text { "Ao ver o Pedro, levante o dedo". Campanha Eleitoral para Deputado } \\
\text { Federal de Pedro Geraldo Costa. }\end{array}$ & \\
\hline $\begin{array}{l}\text { "Mais trabalho, mais oportunidades". Campanha de Candidatura de } \\
\text { Mendonça Filho ao Governo de Pernambuco }\end{array}$ & 2006 \\
\hline $\begin{array}{l}\text { "Novo Maranhão". Campanha de José Sarney ao Governador Maranhão. } \\
\text { "Novo Tempo" Campanha de Roseana Sarney ao Governo Maranhão. }\end{array}$ & $\begin{array}{l}1996 \\
2002\end{array}$ \\
\hline $\begin{array}{l}\text { "Não vote em branco, vote Negrão de Lima". Campanha Eleitoral no Rio } \\
\text { de Janeiro para Governador. }\end{array}$ & \\
\hline $\begin{array}{l}\text { "Os velhos de Brasília não podem ser eternos". Campanha Eleitoral para } \\
\text { Deputado Federal Henrique no Acre. }\end{array}$ & \\
\hline "Tempo Novo". Campanha de Marconi Perillo ao governo Goiás. & \\
\hline $\begin{array}{l}\text { "Juntos vamos mais". Campanha de Paulo Hartung ao Governo do } \\
\text { Espírito Santo. }\end{array}$ & 2006 \\
\hline $\begin{array}{l}\text { "O senador da União". Campanha Eleitoral de Jarbas Vasconcelos ao } \\
\text { senado por Pernambuco. }\end{array}$ & 2006 \\
\hline $\begin{array}{l}\text { "ACM -Ação, Competência e Moralidade". Campanha Eleitoral de } \\
\text { Antônio Carlos Magalhães ao governo da Bahia. }\end{array}$ & \\
\hline $\begin{array}{l}\text { "Brasília nunca mais será a mesma". Campanha Eleitoral de Clodovil } \\
\text { Hernandes para Deputado Federal. }\end{array}$ & 2006 \\
\hline $\begin{array}{l}\text { "Alô Rocinha! Pobre vota em pobre. É nóis na fita!". Campanha para } \\
\text { Deputado de Mauro Galo no Rio de Janeiro. }\end{array}$ & \\
\hline $\begin{array}{l}\text { "Eu era feliz e não sabia". Campanha de Delfim Neto a Deputado } \\
\text { Federal. }\end{array}$ & 1990 \\
\hline “O Paraná faz bem”. Campanha de Álvaro Dias no Paraná. & \\
\hline $\begin{array}{l}\text { "O Rio Grande em primeiro lugar". Campanha de Antônio Brito no Rio } \\
\text { Grande do Sul. }\end{array}$ & \\
\hline $\begin{array}{l}\text { "Ajude um desempregado a virar deputado". Campanha para Deputada de } \\
\text { Lia Preto. }\end{array}$ & \\
\hline "Seu voto? não chute...vote na Ruth. ?" & \\
\hline $\begin{array}{l}\text { "Pra seu governo, nem Miro, nem Sandra". Campanha de Moreira Franco } \\
\text { no Rio de Janeiro. }\end{array}$ & \\
\hline
\end{tabular}




\begin{tabular}{|c|c|}
\hline Tabela 4: Campanhas Municipais & \\
\hline Slogan & Ano \\
\hline $\begin{array}{l}\text { "O tostão contra o milhão". Campanha de Jânio Quadros a Prefeito de } \\
\text { São Paulo. }\end{array}$ & 1953 \\
\hline $\begin{array}{l}\text { "Quem ama São Paulo, vota Paulo." "Foi Maluf que fez". Campanha } \\
\text { Paulo Maluf a Prefeito de São Paulo. }\end{array}$ & 1988 \\
\hline $\begin{array}{l}\text { "Trabalhador vota em trabalhador". Texto adotado pelos candidatos do } \\
\text { PT. }\end{array}$ & 1980 \\
\hline $\begin{array}{l}\text { "Rouba, mas faz" (Ademar de Barros/Paulo Maluf). Esse foi um slogan } \\
\text { popular, que surgiu em épocas distintas para os dois candidatos. O slogan } \\
\text { oficial da campanha de Ademar de Barros era "Fé em Deus e Pé na } \\
\text { Tábua" e o De Maluf era "Quem ama São Paulo, vota Paulo. }\end{array}$ & $1950 / 1988$ \\
\hline "Prefeito da paz". Campanha de Nion Albernaz a Prefeito de Goiânia. & 1966 \\
\hline "Tá certo Paulo Roberto". Campanha a Prefeito de Rio Verde-GO. & \\
\hline "Chega de malas, vote em Bouças". & \\
\hline $\begin{array}{l}\text { 'Lingüiça Neles!". Campanha com grito de guerra do candidato Lingüiça, } \\
\text { de Cotia-SP. }\end{array}$ & \\
\hline "Tudo Pela Dinha".Campanha de Dinha em Descalvado -AL. & \\
\hline $\begin{array}{l}\text { "Não vote em } \mathrm{A} \text {, nem em } \mathrm{B} \text {, nem em } \mathrm{C} \text {; na hora } \mathrm{H} \text {, vote em Gê". } \\
\text { Campanha em Carmo do Rio Claro, do candidato apelidado de Gê. }\end{array}$ & \\
\hline $\begin{array}{l}\text { "Não vote sentado, vote em Pé". Campanha de um candidato de apelido } \\
\text { Pé em Hidrolândia -GO. }\end{array}$ & \\
\hline $\begin{array}{l}\text { "'Vote com prazer". Campanha da candidata chamada Débora Soft, } \\
\text { stripper e estrela de show de sexo explícito no Ceará. }\end{array}$ & \\
\hline $\begin{array}{l}\text { "Pedra no buraco e Pedro na Prefeitura". Campanha a Prefeito de Pedro } \\
\text { Geraldo Costa. }\end{array}$ & \\
\hline $\begin{array}{l}\text { "Vote em Difunto, porque político Bom é político Morto". Campanha em } \\
\text { Mogi das Cruzes-SP, do candidato chamado Difunto. }\end{array}$ & \\
\hline $\begin{array}{l}\text { "Dos males o menor". Campanha de Muniz Freire - ES. O anão Celinho } \\
\text { - Candidato Vereador. }\end{array}$ & \\
\hline $\begin{array}{l}\text { "Chega dos Mesmos". Campanha de Francisco Rossi a Prefeitura de } \\
\text { Osasco. }\end{array}$ & 1985 \\
\hline
\end{tabular}




\begin{tabular}{|l|l|}
\hline $\begin{array}{l}\text { "Leve-me para a Câmara". Campanha da modelo Núbia de Oliveira que } \\
\text { disputou uma cadeira de vereadora pelo PL de Uberaba-MG. }\end{array}$ & 2002 \\
\hline "Vote na filha do Rei, Jesus". Campanha Slogan da filha do Pelé para & 2002 \\
Vereadora em Santos. & \\
\hline "Na hora de votar - CIMATI" - Candidato Cimati a Vereador na cidade & 2002 \\
de Dourados - MS. & \\
\hline
\end{tabular}

\begin{tabular}{|l|l|}
\hline Tabela 5: Apelidos de políticos brasileiros \\
\hline Slogan & Ano \\
\hline $\begin{array}{l}\text { Toninho Ternura/Toninho Malvadeza, ACM (Antonio Carlos } \\
\text { Magalhães/BA). Senador e Governador pelo Estado da Bahia. }\end{array}$ & 1975 \\
\hline FHC( Fernando Henrique Cardoso/SP) Ex-Presidente. & 1990 \\
\hline JK (Juscelino Kubitshceck/MG) Ex-Presidente. & 1955 \\
\hline O velho ,Gegê ( Getúlio Vargas/RS) Ex-Presidente. & 1940 \\
\hline Seu Mé (Artur Bernardes/MG) Ex-presidente. & 1920 \\
\hline $\begin{array}{l}\text { Lula (Luis Inácio Lula da Silva/PE e SP) Ex-sindicalista, um dos } \\
\text { fundadores do PT atual Presidente. }\end{array}$ & 1970 \\
\hline
\end{tabular}

\section{- Clichês}

São slogans/expressões comumente usadas em campanhas de diversos níveis, que normamelmente faz apelos gerais aos cidadãos de uma cidade evocando o nome da cidade: "Vamos ver (o nome da cidade) crescer; "(nome da cidade), novos rumos"; "Por uma (nome da cidade) forte e humana"; "Porque (cidade) merece"; "(cidade), o futuro é agora"; "Eu respeito (cidade)”; “(cidade) mais feliz, (fulano) já ganhou!”; "Não desperdice seu voto!, (cidade) merece mais!"; Compare os (número de candidatos da cidade).Vote certo!"; "Voto !"; "Vote nele!"; “O povo no poder".

\section{PERSPECTIVAS METODOLÓGICAS}

Em termos metodológicos, na investigação presente optamos pela utilização da análise de conteúdo, a partir do modelo de Espírito Santo (2004), inspirada nos estudos de 
Berelson (1946, 1947, 1952) e Bardin (1977), técnica que nos propusemos aplicar, tendo com consideração a sua adequação e tradição na análise descritiva e também inferência de conteúdos comunicacionais como os materiais de propaganda. Além desta, há incursões sobre as definições teóricas sobre o slogan, a partir de Reboul (1975) e Lasswell (1982); e uma visão linguística, a partir das definições de Iasbeck (2002).

Depois disso, enveredamos pelas incursões sobre a evolução histórica da comunicação, conforme o projeto que vimos desenvolvendo sobre A história as eleições presidenciais no Brasil Republicano, sediado na Universidade Metodista de São Paulo. Nesse sentido, o estudo clássico desenvolvido por Harold Laswell e Sergius Yakobson, sobre “Os slogans de $1^{\circ}$ de maio na União Soviética, 1918/1943” (Lasswell 1982), sugerem igualmente a necessidade de releitura para o panorama contemporâneo nacional, mostrando de que forma os slogans evoluíram em campanhas nacionais no nosso país, rico em diversidade lingüística e cultural.

A técnica de análise de conteúdo -com raízes teóricas nos desenvolvimentos norteamericanos das décadas de 30 e, sobretudo, de 40 em diante teve múltiplos contributos impulsionadores pioneiros, entre os quais se destacou o de Bernard Berelson (1952).

Este autor é considerado um dos principais mentores daquela técnica nos EUA. Berelson produziu contributos no plano conceptual e empírico que marcaram a investigação social e política, não só no âmbito da técnica de análise de conteúdo como também nos estudos de propaganda, e nos estudos com base em sondagens e inquéritos sociológicos ligados aos primeiros desenvolvimentos na área do comportamento eleitoral.

O impacto do modelo conceitual e metodológico de Berelson foi significativo, durante várias décadas, não apenas nos EUA, mas conforme assinalou Bardin, em contextos como o francês. Segundo Bardin, pelo menos até a década de 1970, os raros manuais que abordavam a técnica, obedeciam de modo rígido ao modelo de Berelson (Bardin 1977) A partir dos anos de 1980, a perspectiva qualitativa da análise de conteúdo passa a ser alvo de maior destaque conceptual assim como de desenvolvimento empírico. Múltiplos contributos de referência posteriores têm contribuído para a renovação dos enfoques técnicos da análise de conteúdo (Krippendorf 1980; Weber 1990; Romero 1991; Altheide 1996).

$\mathrm{Na}$ aplicação presente da técnica de análise de conteúdo utilizamos a tipologia categorial de Bardin baseada, sobretudo, na inferência sobre os resultados, incidindo, assim, na sua vertente qualitativa. Pretende-se, do ponto de vista categorial e da inferência, a desmontagem das tendências de comunicação constantes no corpus selecionado, constituído pelas mensagens dos slogans. Neste estudo, não temos como objetivo o levantamento e 
inferência de natureza iconográfica dos materiais de propaganda que constituem o todo textual de onde os slogans são parte integrante. Como referido, este estudo tem em consideração uma matriz sociológica, baseada na análise de conteúdo e, como tal, não se enquadra na matriz teórica lingüística que a análise textual e discursiva podem fornecer. Embora o nosso objeto empírico, os slogans de campanhas eleitorais, tenha materialidade textual verbal.

No que se refere ao processo de codificação procedemos ao recorte das unidades de análise, compostas pela palavra e pelo tema. Ainda no âmbito do processo de codificação, a regra de enumeração utilizada é de ordem qualitativa. Ou seja, a escolha das unidades de enumeração é concretizada no levantamento e análise da presença ou ausência de ocorrências com significado analítico, face aos objetivos propostos.

Para além da codificação, a outra operação técnica presente é a categorização. Nesta optou-se por um sistema de classificação semântico, aliado a um procedimento designado 'por milhas'(Bardin 1977).

Optamos por este procedimento tendo em consideração a natureza rica, diversificada e extensa do material em análise. De modo concreto, este procedimento consiste no desenvolvimento do quadro categorial à medida que se desenvolve todo o processo de investigação e amadurecimento das potencialidades de análise do material selecionado. Ou seja, o processo de categorização é ditado, sobretudo, pelos contornos e especificidades do corpus, e procura um alinhamento analítico, de acordo com a sua natureza comunicacional e significados simbólicos.

Desse modo, as operações de codificação e categorização foram concebidos pelos autores do estudo, com base no quadro contextual, temático e metodológico atinente ao estudo presente e de acordo com o objetivo de análise proposto. O tratamento dos dados foi efetuado, tal como referido, com base numa vertente categorial e qualitativa da análise de conteúdo.

Do ponto de vista da validade do estudo investimos na clarificação dos procedimentos metodológicos utilizados, conscientes da especificidade da análise de conteúdo em termos técnicos, à semelhança do que é perfilhado por outros contributos que se dedicam à investigação social e a esta técnica (Bringberg, McGrath 1985; Bowen, Petersen 1999).

O interesse dos autores nos temas da persuasão e propaganda políticas, como por exemplo, Espírito Santo (1997), assim como a atividade docente e também de investigação deste último, com recurso à análise de conteúdo (Espírito Santo, 2004), contribuiu para que 
o caminho percorrido pudesse ser delineado. Do ponto de vista da fidelidade da análise perfilhamos a importância de se clarificar o conjunto de estratégias metodológicas seguidas para a sua concretização. No que se refere ao instrumento conceitual de base deste estudo, que se consubstancia nas categorias, conduzimos a sua formulação de modo a que as mesmas obedecessem às cinco regras fundamentais que lhe conferem a sua fidelidade. São estas a exclusão mútua, a homogeneidade, a pertinência, a objetividade e a produtividade. Ou seja, tendo sido construída num sistema que promoveu a sua flexibilidade e adaptação às particularidades e riqueza do corpus em análise, a concepção das categorias de análise obedeceu, igualmente, nos vários momentos da sua construção, às regras acima referidas.

\section{O SLOGANE A SUA IMPORTÂNCIA POLÍTICA E COMUNICACIONAL}

Como elemento essencial da mensagem em propaganda política, o slogan constitui a base analítica deste estudo. Em termos de mensagem, a propaganda política assenta, fortemente, no valor dos slogans e dos símbolos políticos, como elementos catalisadores da ação política e eleitoral. Como tal, o slogan deve conter características que desencadeiem a sua rápida memorização, do ponto de vista auditivo ou visual. O êxito do slogan passa por aspectos como a simplicidade, a graça, a graciosidade, a fonética. Por outras palavras,

\footnotetext{
"o slogan tem de conter um apelo, suficientemente, simples, facilmente, compreendido e susceptível de ser uma senha de coesão do grupo. Este grupo, o dos adjuvantes da força política quer-se o mais alargado possível, tanto quanto possa permitir o acesso ao Poder" (Espírito Santo 1997: 115).
}

O nosso interesse nas origens da cultura européia e na comunicação conduziu-nos a uma reputada especialista em sânscrito e a encontrar uma provável resposta, ainda mais longínqua, do que a de Reboul (1975), para as origens e o significado etimológico da expressão slogan. Concluímos que existe uma forte possibilidade de a expressão slogan ter a sua origem no sânscrito. Referimo-nos à contribuição da Professora Doutora Maria Margarida Lacerda, especialista em Sânscrito, reputada Professora Jubilada do Instituto Superior de Ciências Sociais e Políticas, da Universidade Técnica de Lisboa, que afirma que as origens da palavra slogan advêm da Língua da família hindo-hitita que é a forma mais antiga do indo-europeu. Esta língua conservou-se durante cerca de um milênio na tradição oral e passou à escrita somente no II milênio d.C. Esta língua hindo-hitita não é falada nem escrita, hoje em dia. A língua indo-européia é ancestral, raiz e base originária de todos os ramos lingüísticos, situados no quadro do amplo contexto cultural indo-europeu. (Espírito 
Santo, 1997: 116).

Nessa perspectiva, o termo slogan viria do hindo-hitita, idioma no qual faz parte a expressão šloka que traduz a ideia de dístico, ou seja, de dois versos formando sentido completo, os quais poderiam estar inseridos em cânticos que ditos, repetidamente, constituíam um apelo à concretização de boas realizações por parte dos seus emissores e, em última análise, para toda a comunidade.

Consideramos altamente provável que a expressão slogan tenha raiz no sânscrito, na expressão šloka, sendo que a fonética e o significado associado à expressão original naquela língua apontam, fortemente, para tal constatação.

Tecnicamente, o slogan eleitoral traduz-se numa frase curta, a qual contém uma componente promocional destinada a captar o interesse do eleitorado, sendo que o slogan, para além disso, pode conter também palavras de ordem dirigidas à ação. Nem todos os slogans contêm palavras de ordem. Para além do slogan, propriamente dito, há ainda uma componente da mensagem ligada àquele, mas distinta, que se concretiza no apelo ao voto, o qual é composto pelas frases que contêm o nome do candidato e o imperativo verbal do voto neste.

O slogan funciona mais pelo seu significante do que pelo seu significado. Do ponto de vista das representações discursivas o slogan assenta mais no seu caráter mobilizador e instrumental e menos na sua capacidade de esclarecimento, do ponto de vista informacional. O slogan contém em si, geralmente, a idéia do todo do produto político (no caso político) que procura promover, mas isso não significa que tenha, necessariamente, que remeter para o ideário político e ideológico da força política em causa.

Como lembra Lasswell (1982: 22), o slogan "é o grito de guerra" e, como tal, o slogan deve apelar às emoções e levar à coesão. O slogan funciona como um promotor de esperança, alento e empenho, em prol de uma causa e, como tal, gera uma adesão cujo caráter incondicional é, geralmente, perfilhado pelos seus promotores.

Nesse sentido, para além da simplicidade, outra das características que confere funcionalidade ao slogan é a sua facilidade de reprodução oral, a qual, em última análise procura a promoção da unidade do grupo, grupo este que pode ser tão amplo quanto à dimensão do Estado.

O slogan constitui um elemento natural à comunicação humana, com lugar no espaço social e político, desde tempos imemoriais. A funcionalidade do slogan, do ponto de vista da comunicação, reservou-lhe lugar cativo e pouco alterado ao longo de, pelo menos, cerca de dois milênios, a crer na sua antiguidade indo-européia. À entrada do terceiro 
milênio, o slogan mantém-se no seu formato original, curto e pragmático, mas simultaneamente, catalisador, emotivo e aglutinador de massas.

No estudo que construiu, denominado A arte dos slogans, Luís Carlos de Assis Yasbeck (2002: 27) afirmou que esses tipos de textos transmitem as seguintes "sensações de verdade":

a. Os slogans mais eficazes desprendem-se do caráter meramente referencial que os liga aos seus objetos, em vantagem das conotações simbólicas; b. Os slogans publicitários criam, provocam elou sedimentam relações funcionais com os demais modos de pensar e agir que estão presentes nos demais sistemas culturais; c. Os slogans não necessitam alimentar-se de elementos periféricos da não-cultura sob pena de se tornarem excessivamente redundantes e, conseqüentemente, obsoletos.

Iasbeck, classifica a família das imagens em cinco ramos, entendendo-se imagem como representação icônica que guarda do seu objeto certa semelhança. E também reproduz os conceitos de que podem ajudar a valorizar e compreender melhor o papel dos slogans não só em campanhas eleitorais, a saber:

- As imagens gráficas, como pinturas, estátuas, desenhos,

- As imagens óticas, aquelas geradas pelo espelhamento e pela projeção,

- As imagens perceptuais, as que nos vêm pelos dados dos sentidos ou perceptos ou pela identificação de sua aparência,

- As imagens mentais aquelas dos sonhos,da memória,da lembrança, a imagem as idéias,

- As imagens verbais, aquelas escritas pelas palavras, sugeridas pelas metáforas. (Iasbeck 2002: 30)

Vale lembrar também que os slogans se aproximam de outras figuras de linguagem igualmente tradicionais, como refrões, adágios, parêmia, jargão, clichê, divisa, lema, palavra de ordem e norma.

Na conclusão da sua pesquisa, Iasbeck nos mostra que o slogan é um texto que reúne, de forma compactada, uma série de informações que podem ser lidas de múltiplas formas, a saber:

- Brevidade: frase sintética que contém, a princípio, apenas termos e expressões absolutamente necessários;

- Condensação: trata-se de um signo que reúne outros tantos signos privilegiando em destaque aqueles julgados mais significativos pelo produtor, em função do públicoalvo; 
- Autoridade: o slogan afirma alguma coisa, mesmo que o faça negando com firmeza e determinação;

- Prestígio: o enunciado busca, direta ou indiretamente, atrair prestígio para o seu objeto, seja ele o produto, a marca,o anunciante ou uma Idéia;

- Anonimato: o leitor não é capaz de identificar com precisão o autor de um slogan, muito embora possa julgá-lo como o anunciante (candidato) que assina a peça publicitária; mesmo nesse caso, a "voz" do slogan não tem dono;

- Ambigüidade: as várias vozes de um slogan fazem dele uma curiosa e atraente forma de comunicação publicitária,

- Humor: os slogans bem-humorados conseguem maior pregnância no leitor ou no ouvinte, facilitando a memorização e instigando a repetição voluntária, o humor inteligente de um slogan transfere prestígio e simpatia ao objeto enunciado;

- Impacto: o slogan tende a quebrar a cadeia viciada da linearidade de forma a causar surpresa, privilegiando o inusitado, tanto em nível sintático quanto semântico, pode provocar leituras curiosas e enriquecedoras;

- Cadência: muitos slogans tiram grande proveito da cadência e da harmonia rítmica, através de intervalos regulares e tonicidade proporcional, para que soem bem aos ouvidos, mesmo quando apenas lidos;

- Comunicação imediata: um bom slogan pode até convencer o leitor a complexas decifrações posteriores, mas ele não pode deixar de possibilitar comunicação imediata, pois a velocidade de uma leitura não suporta grandes reflexões;

- Repetição: o slogan precisa ser de fácil repetição, ou seja, necessita conter elementos que facilitem sua imediata memorização e não o tornem entediante após algumas repetições. Para possibilitar tais efeitos, a harmonia e a cadência da frase, aliadas à brevidade, são essenciais. (Iasbeck 2002: 35)

\section{DIMENSÕES TEÓRICA E PRAGMÁTICA}

Com as visões teóricas adotadas diante da modesta produção acadêmica sobre slogans político-eleitorais, é possível perceber que este estudo contribui para recompor parcelas da memória, com a captação dos slogans mais presentes em nossa história contemporânea, quer seja em eleições presidenciais, estaduais, municipais ou nos que viraram "clichês" de tanta utilização.

Tomando como parâmetros os conceitos sobre "imagens" e os conceitos sobre 
Breve história dos slogans políticos nas eleições do brasil republicano

de Adolpho Queiroz e Carlos Manhanelli

"linguagens", eis nossa visão sobre alguns dos slogans mais importantes que recuperamos sobre as eleições presidenciais. 


\section{Tabela 6: Campanhas Presidenciais}

\begin{tabular}{|c|c|c|c|}
\hline Slogan & Data & Linguagem & Imagem \\
\hline $\begin{array}{l}\text { "Juntos chegaremos lá" - } \\
\text { Afif Domingos, eleição } \\
\text { presidencial de 1990; }\end{array}$ & 1989 & $\begin{array}{l}\text { Repetição, este slogan foi utilizado } \\
\text { pelo candidato por meio da } \\
\text { linguagem "Libras", sinais gestuais } \\
\text { para surdos/mudos, inovando no } \\
\text { processo. Sua característica de } \\
\text { repetição foi essencial no processo. }\end{array}$ & Percepção \\
\hline $\begin{array}{l}\text { "Collor é progresso". } \\
\text { Campanha presidencial de } \\
\text { Fernando Collor de Melo. } \\
\text { "Um novo tempo vai } \\
\text { começar". Fernando Collor } \\
\text { 1989. "Caçador de } \\
\text { marajás". Fernando Collor. }\end{array}$ & 1989 & $\begin{array}{l}\text { Autoridade. Usando a imagem de } \\
\text { que um "marajá" era um funcionário } \\
\text { público que ganhava muito e não } \\
\text { trabalhava direito,o então candidato, } \\
\text { reprisando a mensagem da } \\
\text { "vassoura" de Jânio, igualmente } \\
\text { prometia limpar a corrupção do } \\
\text { funcionalismo público no país. }\end{array}$ & Metáfora \\
\hline $\begin{array}{l}\text { "Meu nome é Enéas". } \\
\text { Campanha Presidencial do } \\
\text { Candidato Enéas Carneiro. }\end{array}$ & 1989 & $\begin{array}{l}\text { Repetição/Humor. Com pequeno } \\
\text { tempo no rádio e televisão para } \\
\text { popularizar seu nome, o candidato } \\
\text { repetia e interpretava exaustivamente } \\
\text { este slogan, que beirava o ridículo, } \\
\text { mas cujo resultado em termos de } \\
\text { memorização e eficiência foi ótimo }\end{array}$ & Verbal \\
\hline $\begin{array}{l}\text { "Diretas já." Movimento } \\
\text { pelas diretas em 1984. "Eu } \\
\text { quero votar pra presidente". } \\
\text { Movimento pelas Diretas } \\
\text { 1984. "Tancredo Já". } \\
\text { Campanha Presidencial de } \\
\text { Tancredo Neves. }\end{array}$ & 1984 & $\begin{array}{l}\text { Cadência/Condensação. A sociedade } \\
\text { tinha como anseio o fim do Regime } \\
\text { Militar e este slogan dava conta de } \\
\text { construir esta perspectiva }\end{array}$ & $\begin{array}{l}\text { Mental/ } \\
\text { sonho }\end{array}$ \\
\hline
\end{tabular}




\begin{tabular}{|c|c|c|c|}
\hline $\begin{array}{l}\text { "Gente em primeiro } \\
\text { lugar". (1994) "O Brasil } \\
\text { não Pode Voltar Atrás. } \\
\text { Avança, } \\
\text { (reeleição para Presidente } \\
\text { de Fernando Henrique } \\
\text { Cardoso em 1998) }\end{array}$ & $\begin{array}{l}1994 \\
\text { e } \\
1998\end{array}$ & $\begin{array}{l}\text { Autoridade. Pobre em criação, o } \\
\text { slogan priorizava indiretamente a } \\
\text { questão social. Autoridade. O então } \\
\text { candidato também queria continuar } \\
\text { governando, sem receber críticas } \\
\text { pelo que já tinha realizado. }\end{array}$ & $\begin{array}{l}\text { Verbal } \\
\text { Mental/ } \\
\text { sonho }\end{array}$ \\
\hline $\begin{array}{lc}\text { "Queremos } & \text { um } \text { País } \\
\text { Decente". } & \text { Campanha } \\
\text { Presidencial } & \text { de } \text { Geraldo } \\
\text { Alckmin. } & \end{array}$ & 2006 & $\begin{array}{l}\text { Remete-se aos mesmos apelos de } \\
\text { Jânio e Collor,de forma mais amena. }\end{array}$ & Verbal \\
\hline $\begin{array}{l}\text { Varre, varre vassourinha - } \\
\text { Jânio }\end{array}$ & 1960 & $\begin{array}{l}\text { Varrer a corrupção que assolava o } \\
\text { país na época. Autoridade, } \\
\text { mostrando que com uma vassoura na } \\
\text { mão, objeto que a maioria da } \\
\text { população possuía em sua própria } \\
\text { casa, seria possível com a autoridade } \\
\text { moral do candidato, acabar com a } \\
\text { corrupção no país. }\end{array}$ & $\begin{array}{l}\text { Icônica/ } \\
\text { Percepção }\end{array}$ \\
\hline 50 anos em $5-\mathrm{JK}$ & 1955 & $\begin{array}{l}\text { Impacto. Com ele o candidato } \\
\text { sugeriu ao povo um tempo de } \\
\text { progresso e muito trabalho. }\end{array}$ & Verbal \\
\hline $\begin{array}{l}\text { "Vote no Brigadeiro. Ele é } \\
\text { bonito e é solteiro". } \\
\text { Campanha Presidencial do } \\
\text { Brigadeiro Eduardo } \\
\text { Gomes. }\end{array}$ & 1945 & $\begin{array}{l}\text { Prestígio, por ser "bonito e } \\
\text { solteiro" significando que ele } \\
\text { poderia ser um bom presidente por } \\
\text { estas razões. }\end{array}$ & Metáfora \\
\hline $\begin{array}{l}\text { "Ele voltará" } \\
\text { Movimento } \\
\text { Queremista , Getúlio } \\
\text { Vargas }\end{array}$ & 1945 & $\begin{array}{l}\text { Repetição/Prestígio. Como Getúlio } \\
\text { já tinha sido presidente e gozava de } \\
\text { prestígio, a intenção era fazê-lo } \\
\text { retornar à presidência. }\end{array}$ & Mental. \\
\hline
\end{tabular}




\section{ANÁLISE}

$\mathrm{O}$ que se percebe, então, na evolução do processo de comunicação e linguagem/imagem, é que os slogans nas eleições presidenciais brasileiras assumiram papéis estratégicos que os confirmaram perante a história. A repetição do combate à corrupção utilizada por Jânio e Collor, é emblemática dos desafios no período. As sínteses “50 anos em 5", "Diretas já”, "Lula lá” uniram sonoridade, ritmo e impacto. E, com certeza, o slogan com a linguagem de "Libras", do candidato Guilherme Afif Domingos, em 1989, foi emblemático do ponto de vista da inclusão social.

A repetição deu ao "Meu nome é Enéas", a característica essencial para que o candidato obtivesse mais de um milhão de votos, usando pouco mais de 30 segundos diários em suas peças de comunicação com a sociedade na programação nacional do Horário Eleitoral Gratuito a partir do rádio e da televisão.

Se sob a ótica da linguagem da imagem as características dos slogans se repetiram ao longo da história recente do país, do ponto de vista da história da propaganda política, estas características se ampliaram com o passar os anos. Se antes eram apenas impressos em jornais, folhetos de divulgação impressa, foi com a chegada do rádio e da televisão que os slogans - e ao lado dele os jingles - ajudaram a popularizar candidatos/candidaturas e foram a síntese necessária para os processo comunicacional e a identificação da sociedade com os seus candidatos preferidos.

\section{REFERÊNCIAS BIBLIOGRÁFICAS}

ALTHEIDE, D. Qualitative Media Analysis. NewburyPark. C.A. Sage Publications. 2006. BARDIN, L. Análise de Conteúdo. Lisboa. Edições70. 1977.

BERELSON, B. Content Analysis in Communication Research. New York. The Free Press. 1952.

; SALTER, P. J. Majority and Minority Americans: An Analysis of Magazine Fiction. In The Public Opinion Quarterly. Oxford. Oxford Journals. v.10. n. 2. 1946. p. $168-190$.

: DE GRAZIA, S. "Detecting Collaboration in Propaganda". In The Public Opinion Quarterly. Oxford. Oxford Journals. v.11. n.2. 1947. p. 244-253.

BOWEN, J; PERTESEN, R. Critical Comparisons in Politics and Culture. Cambridge. Cambridge University Press. 1999. 
BRINGBERG, D. McGRATH, J. Validity and the Research Process. Califórnia. Sage Publications. 1985.

ESPÍRITO SANTO, P. Decisões de Voto - Um Estudo de Sociologia Política acerca das Legislativas de 2002. Lisboa. ISCSP. 2004.Tese de Doutoramento.

O Processo de Persuasão Política -Abordagem Sistémica da Persuasão com Referências ao Actual Sistema Político Português. Lisboa. ISCSP. 1997.

A mensagem política na campanha das eleições presidenciais: análise de conteúdo dos slogans entre 1976 e 2006. In Revista Comunicação \& Cultura. n. 2. Universidade Católica Portuguesa. Lisboa. Quimera. 2006. p. 83-101.

IASBECK, L.C. A arte dos slogans, as técnicas de construção das frases de efeito do texto publicitário. São Paulo. Editora Anablume. 2002.

LESSA, O. Propaganda eleitoral, observações sobre a campanha política na eleição para governador de São Paulo em 1954. Rio de Janeiro. Editora PN. 1955.

KRIPPENDORF, K. Content Analysis -An Introduction to Its Methodology. London. Sage Publications. 1986.

LASSWELL, H. A Linguagem da Política. Brasília. Editora Universidade de Brasília. 1982. Tradução Lúcia Dauster Vivacqua e Silva e Sônia de Castro Neves.

MAGALHÃES, C. \& MOTA, A. Slogans, os 1000 melhores slogans da propaganda brasileira. Rio de Janeiro. Letter editorial. 1991.

QUEIROZ, A. (Coord.). Marketing político brasileiro. Ensino, pesquisa e mídia. Limeira. INTERCOM/ Cátedra UNESCO. Unigráfica. 2005.

REBOUL, O. O slogan. Editora Cultrix. São Paulo.1975.

ROMERO, A. Metodologia da Análise de Conteúdo. Lisboa. Universidade Católica Portuguesa. 1991.

WEBER, R. P. Basic Content Analysis. 2ed. Newbury Park Califórnia. Sage Publications. 1990.

http://pt.wikipedia.org/wiki/Slogan acessado em 28/11/2007 9:30h.

Artigo recebido em 20/8/2009.

Aprovado em 27/9/2009. 